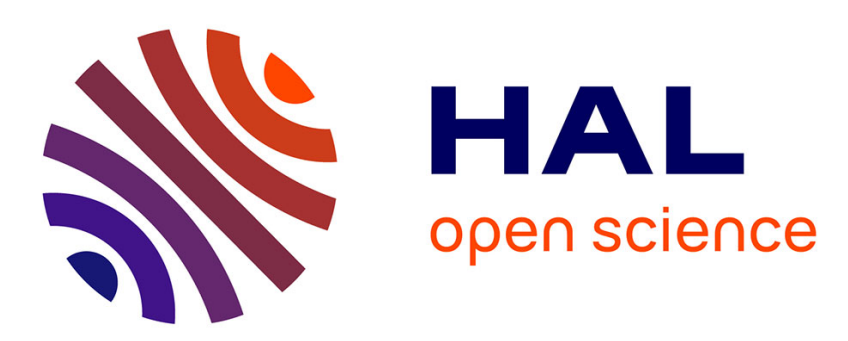

\title{
Advanced diagnostics applied to fish liver tumours: relating pathology to underlying molecular aetiology
}

Adelaide Lerebours, John P Bignell, Grant D Stentiford, Stephen W Feist, Brett P Lyons, Jeanette M Rotchell

\section{To cite this version:}

Adelaide Lerebours, John P Bignell, Grant D Stentiford, Stephen W Feist, Brett P Lyons, et al.. Advanced diagnostics applied to fish liver tumours: relating pathology to underlying molecular aetiology. Marine Pollution Bulletin, 2013, 72 (1), pp.94-98. 10.1016/j.marpolbul.2013.04.016 . hal-02155169

\author{
HAL Id: hal-02155169 \\ https://hal.science/hal-02155169
}

Submitted on 13 Jun 2019

HAL is a multi-disciplinary open access archive for the deposit and dissemination of scientific research documents, whether they are published or not. The documents may come from teaching and research institutions in France or abroad, or from public or private research centers.
L'archive ouverte pluridisciplinaire HAL, est destinée au dépôt et à la diffusion de documents scientifiques de niveau recherche, publiés ou non, émanant des établissements d'enseignement et de recherche français ou étrangers, des laboratoires publics ou privés. 


\title{
Advanced diagnostics applied to fish liver tumours: relating pathology to underlying molecular aetiology
}

\author{
${ }^{1}$ Adélaïde Lerebours, ${ }^{2}$ John P. Bignell, ${ }^{2}$ Grant D. Stentiford, ${ }^{2}$ Stephen W. Feist, \\ ${ }^{2}$ Brett P. Lyons and ${ }^{1}$ Jeanette M. Rotchell* \\ ${ }^{1}$ Department of Biological Sciences, University of Hull, Cottingham Road, Hull, \\ HU6 7RX, United Kingdom \\ ${ }^{2}$ Centre for Environment, Fisheries and Aquaculture Science, Weymouth \\ Laboratory, Barrack Road, The Nothe, Weymouth, Dorset DT4 8UB, United \\ Kingdom
}

Keywords: Laser microdissection, frozen sections, fish cancer, tumourigenesis, retinoblastoma gene

*Corresponding author: Jeanette M. Rotchell, e-mail: J.Rotchell@Hull.ac.uk, phone number: +44 (0) 1482 465333, fax number: +44 (0) 1482465458 


\begin{abstract}
Liver tumours in flatfish have been diagnosed using histopathology for decades in order to monitor the impacts of marine pollution in coastal and estuarine environments. This traditional method has been coupled with molecular analyses of tumours in the liver of the dab, Limanda limanda, in order to elucidate underpinning molecular level aetiology of such disease. A laser capture microdissection technique for molecular investigation of cancer has been applied in fish. The present study provides optimized steps for environmental sample utilisation: a procedure for field sample collection and handling; a method allowing reliable identification of lesions on frozen tissue sections; and, downstream molecular analyses of tumourigenesis markers (retinoblastoma gene) in laser microdissected samples. This approach facilitates the use of wild flatfish as a model of environmentally-induced tumourigenesis, and has wide applicability to any disease pathology for which the underpinning molecular aetiology is required.
\end{abstract}




\section{Introduction}

Since the 1980s, liver pathologies of flatfish dab, Limanda limanda, English sole, Parophrys vetulus, and European Flounder (Platichthys flesus) have been used to monitor the effects of exposure to marine pollution (Malins et al., 1985; Vethaak and Reinallt, 1992; Stentiford et al., 2003; Lyons et al., 2004). Such lesions have been associated with exposure to anthropogenic contaminants such as polycyclic aromatic hydrocarbons (PAHs) (Malins et al., 1985; Vethaak and Reinallt, 1992). Dab possess both a similar histopathological tumour profile to humans (Stern and Zon, 2003) and homologs of human cancer genes such as ras and retinoblastoma $(R b)$, including mutational alterations of the $R b$ gene in tumour tissues (Du Corbier et al., 2005). In this respect, we have previously proposed that the dab tumour model could act as surrogate for cancer and the tumourigenesis process in human populations (Rotchell et al., 2009). Studies using this species also facilitate a better understanding of chemically-induced carcinogenesis in wild animals.

Histopathology of tumours and pre-tumours in dab liver are currently diagnosed via a quality assured process involving histological tissue sections generated from wax-embedded samples (Feist et al., 2004). Within the UK, such samples are collected and results are reported under the U.K. Clean Seas Environmental Monitoring Programme (CSEMP) (Stentiford et al., 2009). This diagnostic approach has recently been coupled with molecular analyses of tumour and surrounding non-tumour tissues (Small et al., 2010). In addition, gross lesions and apparently normal tissues have been resected from the dab liver for molecular investigations such as genetic alterations of cancer genes (Du Corbier et al., 2005; Rotchell et al., 2009), transcriptomic (Small et al., 2010), proteomic (Stentiford et al., 2009) and metabolomic studies (Stentiford et al., 2009; Southam et al., 2008). However challenges still remain, particularly in the ability to harvest pure 
populations of cells, to investigate the molecular profile of small lesions in the apparently nontumour part of the liver, and to dissect small and early-stage tumours.

Microdissection and molecular analysis of pure populations of cells presents a challenge in that cellular heterogeneity within tissues samples may result in misleading findings (Cole et al., 1999; Sluka et al., 2008). Laser Capture-Microdissection (LCM) allows the ability to view and microdissect target cells, thereby providing a direct link between a specific histopathological lesion and the molecular profile of that lesion (Gillespie et al., 2001). Successful application of LCM is dependent on tissue morphology, capture success and maintenance of molecular integrity (Sluka et al., 2008). Compared to formalin-fixed paraffin embedded (FFPE) samples, cryogenically preserved samples are preferable for molecular analysis (particularly of RNAs) of LCM-derived samples (Guillespie et al., 2001; Sluka et al., 2008; Erickson et al., 2009). However, since the majority of diagnostic protocols in fish (and other hosts) are based upon use of FFPE-derived histological sections, an inherent difficulty in distinction of specific lesions types exist (Guillespie et al., 2001; Sluka et al., 2008; Vinas and Piferrer, 2008; Jorgensen et al., 2009). LCM has previously been applied to pathological studies in aquatic organisms including fish (Vinas and Piferrer, 2008; Jorgensen et al., 2009), cnidarians (Wiebring et al., 2010), and crustaceans (Small et al., 2008). While some LCM-based studies using frozen sections have been successful (Kitahashi et al., 2009), others have reported difficulty in the recognition of cells or lesions of interest within frozen sections mounted on membrane slides (Vinas and Piferrer, 2008; Jorgensen et al., 2009).

The present study aims at overcoming the challenges remaining in consistent application of LCM for molecular investigations of cancer in wild fish models. We have optimized field sample collection and handling at sea, the detection and classification of lesions on frozen tissue 
sections, and the downstream molecular analyses of carcinogenic markers in LCM-derived samples.

\section{Material and Methods}

Sample Collection. L. limanda were captured at UK Clean Seas Environmental Monitoring (CSEMP) sites on the Dogger Bank, North Sea during July 2008 and 2009 using 30 min tows of a standard Granton trawl aboard the RV Cefas Endeavour. Upon landing, fish were immediately removed from the catch and placed into flow-through tanks containing aerated seawater. The sex, size (total length), and presence of external signs of disease were noted for each fish using methodology specified by the International Council for the Exploration of the Sea (Feist et al., 2004). A total of 72 fish were used in this study. Following euthanasia, the body cavity was opened and the liver was assessed for the presence of macroscopic liver tumours according to the guidelines set out by Feist et al. (2004). For each fish, a standardised cross-section was obtained, placed into a pre-labelled histology cassette and fixed for $24 \mathrm{~h}$ in $10 \%$ neutral buffered formalin before transfer to $70 \%$ industrial methylated spirit. An additional tissue cross-section was also obtained from the site immediately adjacent to the formalin-fixed sample. The sample was embedded in Optimum Cutting Temperature (OCT) media (RA Lamb, U.S.A.) and frozen immediately in a cryobath containing iso-pentane and stored at $-80^{\circ} \mathrm{C}$ for subsequent lasercapture microscopy and molecular investigations. The sampling protocol allowed for a direct comparison of lesions in formalin fixed and cryopreserved samples of liver.

Sample processing. An overview of the sample processing regime is shown in Fig. 1. Formalin-fixed paraffin embedded (FFPE) samples of liver were prepared by vacuum infiltration processing by using standard protocols (Feist et al., 2004). Following embedding, sections were 
cut at 3-5 $\mu \mathrm{m}$ on a rotary microtome, and resulting tissue sections were mounted on glass slides before staining with haematoxylin and eosin (HE). Stained sections were analysed by light microscopy (Elipse E800, Nikon, U. K.) and the diagnosis of liver tumour type followed guidelines set out by Feist et al. (2004).

Appropriate frozen samples were selected according to the presence and identification of lesions in the corresponding FFPE sections. OCT-embedded liver samples were transferred to a cryostat adjusted to $-20^{\circ} \mathrm{C}$. Samples were attached to a specimen disk with liquid OCT and allowed to freeze and harden within the cryostat chamber. For each liver sample, two frozen sections were cut and collected onto a clean glass slide. Sections were cut at $8 \mu \mathrm{m}$ (a cutting thickness previously shown to give efficient yields of high quality RNA without an excessive increase in tissue opacity, or chance of dissecting unwanted cells). Sections were subsequently stained according to a protocol adapted from Huang et al. (2002). Glass slides were immediately placed into 70\% ethanol for 2-4 min and then rinsed in DEPC water. Mayer's hematoxylin stain was applied to the slide surface for 2 min followed by a rinse in DEPC-treated water. The slides were then incubated in Scott's bluing solution (Leica Microsystems, U. K.) for 30s followed by a rinse in DEPC water and a rinse in $70 \%$ ethanol. Eosin stain was applied for 45 s followed by dehydration in $95 \%$ ethanol for 30s, in $100 \%$ ethanol for 1 min and two baths of xylene of 1 min each. Glass slides were mounted with DePex prior to microscopic evaluation. Frozen sections were screened to determine whether those lesions previously observed and classified within FFPE liver sections, were also present in the frozen sections. Specifically, the histopathological lesions of interest for the purposes of this study were: control (no abnormalities detected), vacuolated foci of cellular alteration (vFCA), eosinophilic FCA (eFCA), basophilic FCA (bFCA), hepatocellular adenoma (HCA) and hepatocellular carcinoma (HCC). Upon 
identification, digital images of histological lesions were obtained using the Lucia G Screen Measurement System (Nikon U.K. Ltd., Kingston-upon-Thames, U.K.). Two to five frozen tissue sections (depending on the size of the lesion) were collected onto membrane slides for LCM applications from fish that displayed no abnormalities and from lesions of interest in fish displaying tumours. Membrane slides were immediately placed in $70 \%$ ethanol on ice prior to staining as described above, followed by subsequent air drying. During this process, interspersed frozen sections were also obtained and collected onto glass slides (in between those collected for LCM) and stained as described above for further histological assessment. These additional sections allowed for the determination of the nature and localisation of the lesions (due to the reduced image quality when using LCM membrane slides) (Fig. 1). They also served as a record of the lesion type within a specific sample.

Tissue Microdissection. Laser micro-dissections were performed using the MMI Cellcut system (Molecular Machines and Industries, Switzerland). The system comprised an inverted microscope (Nikon) with a motorised stage attached to a computer with digital camera, panel monitor and a fixed ultraviolet (cold) laser source. Micro-dissected samples were recovered (captured) by mechanically lowering and raising an adhesive isolation cap (attached to a $0.5 \mathrm{~mL}$ collection tube) on to the membrane following laser cutting. Sections of 3 sizes were selected for the molecular optimization step. The largest area corresponds to a section surface of $1.0 \times 10^{7}$ $\mu \mathrm{m}^{2}$, the intermediate to a section surface of $4.2 \times 10^{5} \mu \mathrm{m}^{2}$ and the smallest to a section surface of $1.4 \times 10^{5} \mu \mathrm{m}^{2}$. These sections represented the amount of tissue microdissected from a large tumour, a medium-sized tumour, and a pool of three to five small pre-tumours (FCAs) respectively. 
Total RNA isolation and cDNA synthesis. Total RNAs were extracted using the Absolutely RNA Microprep Kit (Stratagene, La Jolla, U.S.A.) according to the supplier's instructions. The optional DNase treatment was found to decrease the concentration of RNAs and was not suitable for our analyses. The elution step was repeated 2 times in a volume of $15 \mu \mathrm{L}$. The quality of RNA (the integrity of the 18 and 28S ribosomal bands) for the largest sections was evaluated by electrophoresis on a $1 \%$ agarose-formaldehyde gel.

First strand cDNAs were synthesized from $14 \mu \mathrm{L}$ of total RNA using the SuperScript® VILO $^{\mathrm{TM}}$ cDNA Synthesis Kit (Invitrogen Ltd, Paisley, U. K.) and according to the supplier's instructions. The duration of the retro-transcription phase was $90 \mathrm{~min}$.

Retinoblastoma $(\boldsymbol{R} \boldsymbol{b})$ cDNA isolation. Different lengths of $R b$ fragments were amplified in order to find the maximum length yielding a reliable sequencing resolution from microdissected samples. Following this, three overlapping parts of the coding sequence of the $R b$ cDNA: RbA1, $\mathrm{RbA} 2$ and $\mathrm{RbB}$, containing the region of functional importance, $\mathrm{A}$ and $\mathrm{B}$, were amplified. Primer pairs used to amplify the region comprised between 620 and $1942 \mathrm{bp}$ of the $R b$ cDNA (Accession number: AY973250) are described in Table 1. Next, 2 or $4 \mu \mathrm{L}$ of the reverse transcribed product was used as a template for subsequent PCR in a $25 \mu \mathrm{L}$ final volume using 2.5 units of the Expand High FidelityPLUS enzyme (Roche Diagnostics Ltd, West Sussex, U. K.), primers at a final concentration of $1 \mu \mathrm{M}$, and following the supplier's instructions. PCR reactions were performed according to the following programme: one cycle at $94^{\circ} \mathrm{C}$ for 2 min and 40 amplification cycles at $94^{\circ} \mathrm{C}$ for $30 \mathrm{~s}, 60^{\circ} \mathrm{C}(\mathrm{RbA} 1)$ or $65^{\circ} \mathrm{C}(\mathrm{RbA} 2$ and $\mathrm{RbB})$ for $30 \mathrm{~s}$, and $72^{\circ} \mathrm{C}$ for 1 min. $10 \mu \mathrm{L}$ of each PCR product were then sequenced commercially (Macrogen, Amsterdam, Netherlands). 


\section{Results}

Histopathological assessment using frozen sections. Histopathological liver lesions in dab were characterised according to Feist et al. (2004). FCAs refer to the early stages in liver tumour development, appearing as discrete collections of hepatocytes displaying atypical staining and morphological characteristics (Fig. 2A, 2B and 2C). Vacuolated FCAs were comprised of lipidvacuolated hepatocytes in which the nuclei are generally displaced to the cell margins, a result of the relatively high cytoplasmic lipid content (Fig. 2A). Basophilic FCAs were comprised of hepatocytes, staining relatively pink-purple compared to surrounding liver parenchyma (a result of proliferated the rough endoplasmic reticulum) (Fig. 2B). Eosinophilic FCAs appeared as pale pink accumulations, due to the proliferation of smooth endoplasmic reticulum within the cell cytoplasm (Fig. 2C). Tumour diagnoses corresponded to the lesion types hepatocellular adenoma (HCA) and hepatocellular carcinoma (HCC). HCAs were diagnosed by their distinctive border, compression of the surrounding blood vessels, a relative absence of melanomacrophage aggregates (MMAs) and other architectural alterations compared to the surrounding parenchyma (Fig. 2D). However, some absence of compression was noted for certain HCA samples. HCCs were characterized by a lack of clear differentiation relative to the surrounding parenchyma, pronounced nuclear and cellular atypia within the lesion, and a loss of normal tissue architecture (Fig. 2E).

These lesions were comparable to those observed in FFPE tissue sections, thus, it was possible to use the frozen sections to classify tumour and each pre-tumour types. The optimised cryotomy method used paint brushes to reduce damage to tissue sections. Frozen sections were collected on a glass slide and mounted with a cover slip, in order to perform a reliable histological examination and comparison with the slides displaying the FFPE tissue section. The results of 
FFPE tissue section and frozen section were identical. The lesions corresponding to pre-tumour (eFCA, bFCA and vFCA) and tumour (HCA and HCC) were successfully identified.

Downstream molecular analyses: Amplification and sequencing of $\boldsymbol{R} \boldsymbol{b}$ cDNA. In terms of optimisations, the transcripts of the three overlapping fragments: RbA1 (450 bp), RbA2 (454 bp) and $\mathrm{RbB}$ (592 bp), of the $R b \mathrm{cDNA}$ from $L$. limanda from the large tissue section $\left(1.0 \times 10^{7} \mu \mathrm{m}^{2}\right)$ were successfully amplified (Fig. 3.) and sequenced. RbA1 fragment was also amplified (Fig. 3.)

and sequenced using the medium $\left(4.2 \times 10^{5} \mu \mathrm{m}^{2}\right)$ and small $\left(1.4 \times 10^{5} \mu \mathrm{m}^{2}\right)$ tissue sections. However, amplifications of RbA2 and $\mathrm{RbB}$ fragments were not detected in section samples smaller than $1.0 \times 10^{7} \mu \mathrm{m}^{2}$. The $R b$ cDNA fragments amplified were all sufficient yield to facilitate commercial sequencing.

\section{Discussion}

Pathological review using frozen sections. The procedure for field sample collection and handling at sea led to a reliable histopathological diagnosis while preserving RNAs for downstream analyses. Therefore, this procedure could be applied to other marine fish species used in biomonitoring programmes. This microdissection-based study details, for the first time, a simple tissue processing strategy which results in clear cellular detail of liver lesion types within frozen tissue sections (Fig. 2). The method facilitates reliable detection of early microscopic pretumour lesions (such as FCA), through to neoplastic lesions such as HCA and HCC in dab (Fig. 2). The examination of pathologies in frozen tissue sections is considered challenging, especially with regard to distinguishing discrete cell populations of interest (Sluka et al., 2008; Erickson et al., 2009) such as pre-tumours and small tumours (Gillespie et al., 2001). This problem is further compounded when attempting to use frozen sections mounted on to LCM membrane slides due 
to the poor refractive light index caused by a combination of the LCM slide membrane, lack of cover slip and its accompanying mountant (Simone et al., 1998). Several authors have applied LCM to the study of aquatic animal tissue structure. Vinas and Piferrer (2008), studied spermatogenesis in the Sea bass Dicentrarchus labrax using the LCM tool to harvest cells from testicular cysts. Jorgensen et al. (2009) applied similar approaches to microdissect the gonads from the zebrafish Danio rerio highlighting the difficulties in recognizing the cells of interest. The present work facilitates reliable pathological studies of tumourigenesis on frozen sections, including the diagnosis of pre-tumours.

Herein, we also provide a method allowing comparison between the glass slide pathology review of a frozen section with an adjacent membrane-mounted section (Fig.1). This facilitates the potential for cells of interest to be reliably targeted for laser-microdissection as well as providing a direct correlation between the molecular profile and histopathology of specific lesions. Previous experiments compared the histopathological diagnosis on the wax-embedded cross sections with molecular data obtained from other sections of fresh liver corresponding to a gross tumour or a non-tumour tissue (Du Corbier et al., 2005; Stentiford et al., 2005; Southam et al., 2008; Rotchell et al., 2009; Small et al., 2010). Since cells have specific functions in an organ or tissue it is important to obtain the molecular signature from the specific cells of interest. Small et al., (2010) suggested, for instance, that variation found in transcriptional profiles from dab liver tumour samples may be due to the resection from different parts of the tumour. The method described reduces heterogeneity in the cell population sampled.

Downstream molecular analyses applications. In this instance the protocols were optimized to analyze molecular level alterations in the $R b$ cDNA to elucidate its role in fish liver tumourigenesis. One benefit of the optimization methods described herein is the reduction of the 
number of overlapping fragments of the gene from six to three for reliable sequencing results as compared to a previous study (Du Corbier et al., 2005). This leads to a significant reduction in time and cost of the experiments. Moreover, molecular optimizations were achieved using affordable reagents and standard commercially-available kits. Most importantly, the method also allowed analysis of the full spectra of tumour types including, for the first time, the difficult small pre-cancerous lesions where molecular alterations potentially first appear. The development of cancer has been viewed as a progressive multi-step process involving the transformation of normal cells into malignant cells via accumulated molecular level alterations in 'cancer genes' such as ras and $R b$. The loss of function of the $R b$ gene occurs by mutation or deletion and results in a diverse set of cancer including hepatocellular carcinoma (Zhang et al., 1994). Du Corbier et al. (2005) reported $R b$ mutations in liver adenoma tissues from dab and suggested that such alterations appear to be involved in the molecular aetiology of environmentally-induced fish tumours. The analysis of early molecular events occurring at the earliest stages of tumourigenesis, in the FCAs, offers the opportunity to better understand the molecular aetiology of fish tumourigenesis and to investigate the search of early biomarkers of contaminant-induced genotoxic damage.

In summary, we describe and pilot a procedure to obtain frozen samples, microdissected from the full spectra of tumour types and the optimization of the downstream molecular analyses. In this instance, the approach is applied to flatfish cancer in the assessment of marine ecosystem health. 
Acknowledgment. The authors are grateful to Kelly Bateman, Tim Bean and Mathew Green for their scientific and technical support. Samples were obtained and all histopathology read under Defra contract SLA24 (to JB).

\section{References}

Cole, K. A., D. B. Krizman, et al. (1999). "The genetics of cancer - A 3D model." Nature Genetics 21(1 SUPPL.): 38-41.

Du Corbier, F. A., G. D. Stentiford, et al. (2005). "Isolation of the retinoblastoma cDNA from the marine flatfish dab (Limanda limanda) and evidence of mutational alterations in liver tumors." Environmental Science and Technology 39(24): 9785-9790.

Erickson, H. S., P. S. Albert, et al. (2009). "Quantitative RT-PCR gene expression analysis of laser microdissected tissue samples." Nature Protocols 4(6): 902-922.

Feist, S. W., T. Lang, et al. (2004). "Biological effects of contaminants: use of liver pathology of the European flatfish dab (Limanda limanda L.) and flouder (Platichthys flesus L.) for monitoring." ICES Techniques in Marine Environmental Sciences (38): 42.

Gillespie, J. W., M. Ahram, et al. (2001). "The role of tissue microdissection in cancer research." Cancer Journal 7(1): 32-39.

Jorgensen, A., J. E. Nielsen, et al. (2009). "Laser capture microdissection of gonads from juvenile zebrafish." Reproductive Biology and Endocrinology 7: 97.

Kitahashi, T., S. Ogawa, et al. (2009). "Cloning and expression of kiss2 in the zebrafish and medaka." Endocrinology 150(2): 821-831. 
Lyons, B. P., G. D. Stentiford, et al. (2004). "DNA adduct analysis and histopathological biomarkers in European flounder (Platichthys flesus) sampled from UK estuaries." Mutation Research - Fundamental and Molecular Mechanisms of Mutagenesis 552(1-2): 177-186.

Malins, D. C., M. M. Krahn, et al. (1985). "Toxic-Chemicals in Marine Sediment and Biota from Mukilteo, Washington - Relationships with Hepatic Neoplasms and Other HepaticLesions in English Sole (Parophrys Vetulus)." Journal of the National Cancer Institute 74(2): 487-494.

Rotchell, J. M., F. A. du Corbier, et al. (2009). "A novel population health approach: Using fish retinoblastoma gene profiles as a surrogate for humans." Comparative Biochemistry and Physiology - C Toxicology and Pharmacology 149(2): 134-140.

Simone, N. L., R. F. Bonner, et al. (1998). "Laser-capture microdissection: Opening the microscopic frontier to molecular analysis." Trends in Genetics 14(7): 272-276.

Sluka, P., L. O'Donnell, et al. (2008). "Application of laser-capture microdissection to analysis of gene expression in the testis." Progress in Histochemistry and Cytochemistry 42(4): 173201.

Small, H. J., J. Sturve, et al. (2008). "Laser-assisted microdissection: A new tool for aquatic molecular parasitology." Diseases of Aquatic Organisms 82(2): 151-156.

Small, H. J., T. D. Williams, et al. (2010). "Gene expression analyses of hepatocellular adenoma and hepatocellular carcinoma from the marine flatfish Limanda Limanda." Diseases of Aquatic Organisms 88(2): 127-141. 
Southam, A. D., J. M. Easton, et al. (2008). "Metabolic changes in flatfish hepatic tumours revealed by NMR-based metabolomics and metabolic correlation networks." Journal of Proteome Research 7(12): 5277-5285.

Stentiford, G. D., J. P. Bignell, et al. (2009). "Site-specific disease profiles in fish and their use in environmental monitoring." Marine Ecology Progress Series 381: 1-15.

Stentiford, G. D., M. Longshaw, et al. (2003). "Histopathological biomarkers in estuarine fish species for the assessment of biological effects of contaminants." Marine Environmental Research 55(2): 137-159.

Stentiford, G. D., M. R. Viant, et al. (2005). "Liver tumors in wild flatfish: A histopathological, proteomic, and metabolomic study." OMICS A Journal of Integrative Biology 9(3): 281299.

Stern, H. M. and L. I. Zon (2003). "Cancer genetics and drug discovery in the zebrafish." Nature Reviews Cancer 3(7): 533-539.

Vethaak, A. D. and T. ap Rheinallt (1992). "Fish disease as a monitor for marine pollution: the case of the North Sea." Reviews in Fish Biology and Fisheries 2(1): 1-32.

Vinas, J. and F. Piferrer (2008). "Stage-specific gene expression during fish spermatogenesis as determined by laser-capture microdissection and quantitative-PCR in sea bass (Dicentrarchus labrax) gonads." Biology of Reproduction 79(4): 738-747.

Wiebring, A., H. Helmholz, et al. (2010). "Separation and analysis of different types of nematocysts from Cyanea capillata (L.) medusae." Hydrobiologia 645(1): 203-212. 
Zhang, X., H. J. Xu, et al. (1994). "Deletions of chromosome 13q, mutations in retinoblastoma 1, and retinoblastoma protein state in human hepatocellular carcinoma." Cancer Research 54(15): 4177-4182.

\section{Figure and Table legends}

Figure 1. Overview of the method used to diagnose lesions in frozen sections.

Figure 2. Images of frozen sections collected on glass slides. The lesions represented are some foci of cellular alteration (FCA): vacuolated FCA (A), basophilic FCA (B) and eosinophilic FCA (C), a benign neoplasm: an hepatocellular adenoma (D) and a malignant neoplasm: an hepatocellular carcinoma $(\mathrm{E})$.

Figure 3. $R b$ cDNA PCR products analysed on $1 \%$ agarose gel. Lanes 1,2 and 3 show the RbA1 (450 bp), RbA2 (454 bp) and RbB (592 bp) fragments respectively obtained from the large section $\left(1.0 \times 10^{7} \mu \mathrm{m}^{2}\right)$ after 1 run of PCR using $2 \mu \mathrm{L}$ of reverse transcripts. Lane 4 shows the RbA1 fragment obtained from the medium section sample $\left(4.2 \times 10^{5} \mu \mathrm{m}^{2}\right)$ after 1 run of PCR using $4 \mu \mathrm{L}$ of reverse transcripts. Lane 5 shows the RbA1 fragment obtained from the small section sample $\left(1.4 \times 10^{5} \mu \mathrm{m}^{2}\right)$ after 2 runs of PCR using $4 \mu \mathrm{L}$ of reverse transcripts. Lane $\mathrm{C} 1$, $\mathrm{C} 2, \mathrm{C} 3, \mathrm{C} 4$ and $\mathrm{C} 5$ are the corresponding negative controls.

Table 1. Oligonucleotide sequences of primer pairs used to amplify and sequence the $R b \mathrm{cDNA}$ region between 620 and 1942 bp. ${ }^{\text {a } F o r w a r d ~ p r i m e r . ~}{ }^{\text {b }}$ Reverse primer. 
Figure 1.

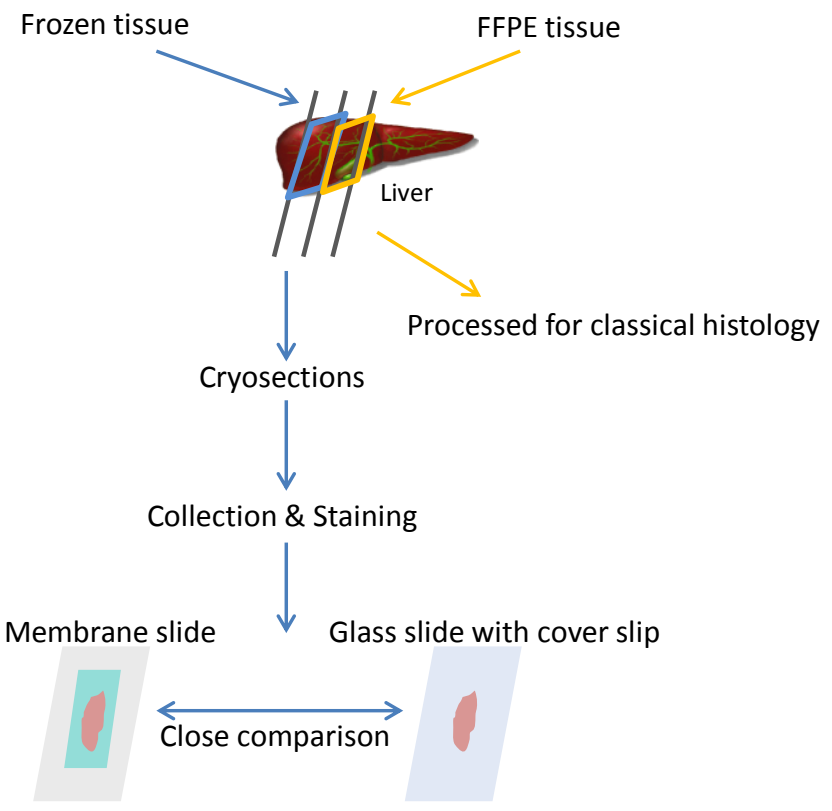




\section{Figure 2.}

A

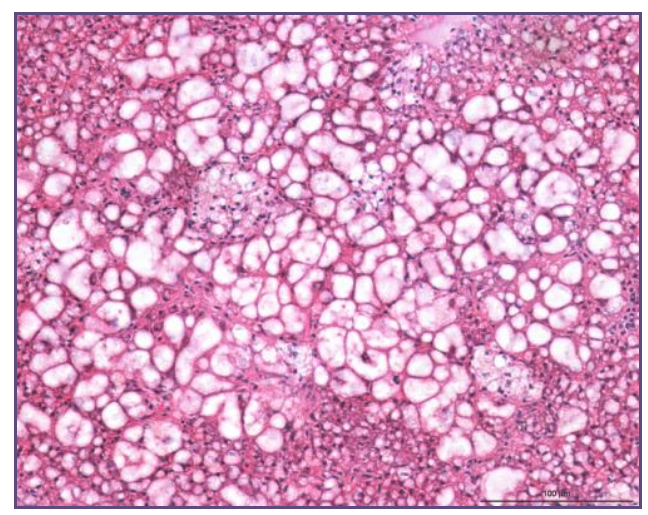

C

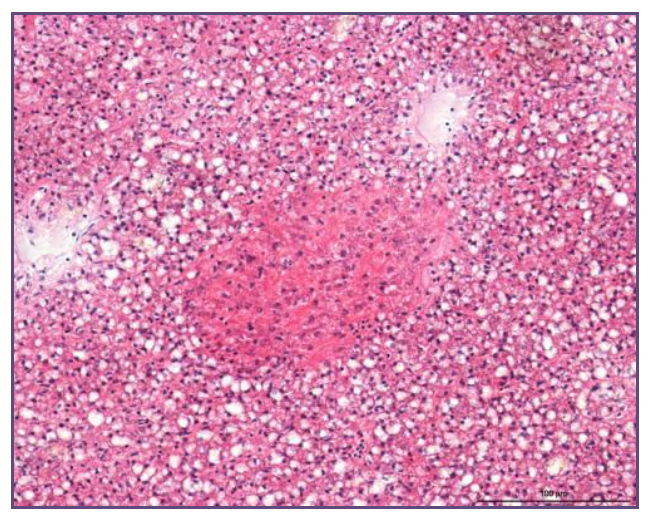

E

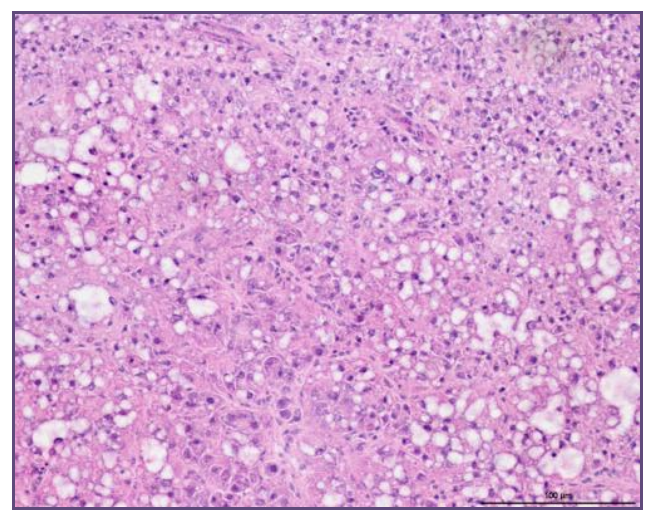

B

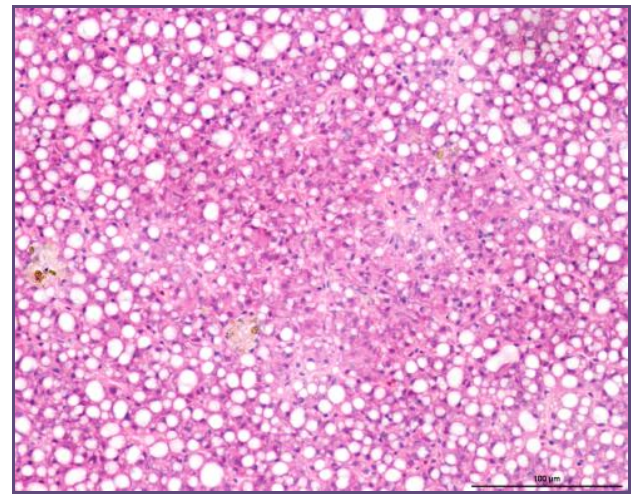

D

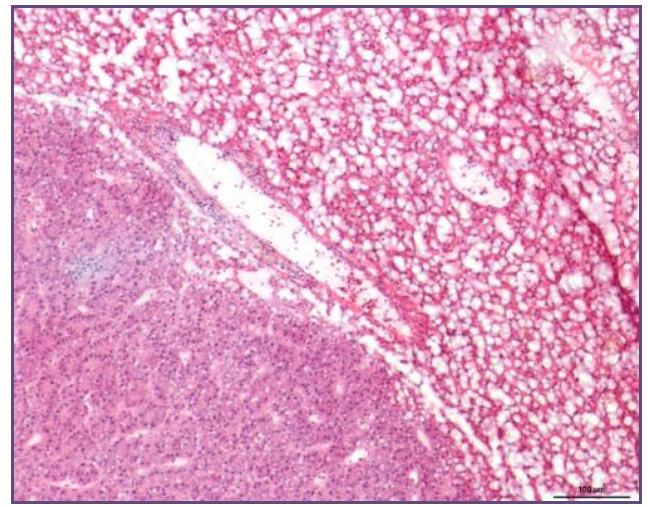


Figure 3.

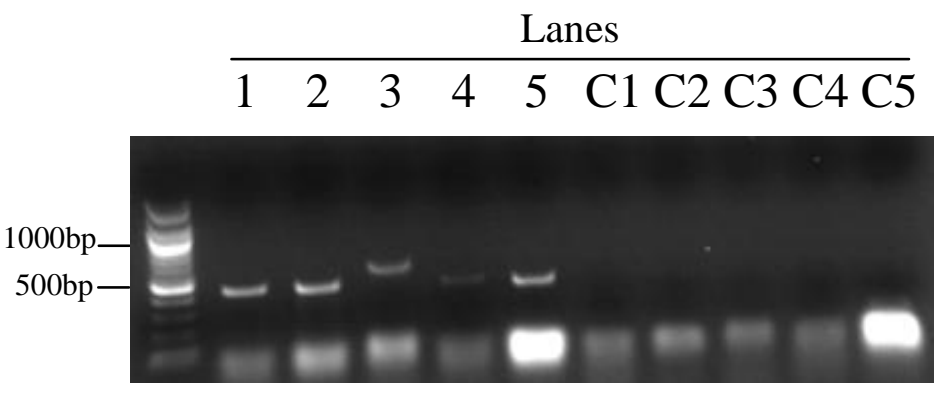


Table 1

\begin{tabular}{cl}
\hline Region of $\boldsymbol{R} \boldsymbol{b}$ cDNA amplified & \multicolumn{1}{c}{ Primer sequence (5'-3') } \\
\hline RbA1: $620 \mathrm{bp}-1070 \mathrm{bp}$ & AATCAGAGCTGCCATGACCT \\
& CCAGGGGAAACAAACATCTG $^{\mathrm{a}}$ \\
RbA2: $983 \mathrm{bp}-1437 \mathrm{bp}$ & GGCAGCATATGGAGAGAGCGG $^{\mathrm{a}}$ \\
& GAGCAGGCGGCTGGGTTGG $^{\mathrm{b}}$ \\
$\mathrm{RbB}: 1350 \mathrm{bp}-1942 \mathrm{bp}$ & CGTCCGGGCCATCGTGTCTT $^{\mathrm{a}}$ \\
& ACGTTGTTGCTGCCAGGCACA $^{\mathrm{b}}$ \\
\hline
\end{tabular}

